\title{
Genetic analysis of fertility-related diseases and disorders in Norwegian Red cows
}

\author{
B. Heringstad ${ }^{*} \dagger^{1}$ \\ *Department of Animal and Aquacultural Sciences, Norwegian University of Life Sciences, PO Box 5003, N-1432 Ås, Norway \\ †Geno Breeding and A. I. Association, PO Box 5003, N-1432 Ås, Norway
}

\begin{abstract}
Heritability of and genetic correlations among silent heat $(\mathrm{SH})$, cystic ovaries $(\mathrm{CO})$, metritis (MET), and retained placenta $(\mathrm{RP})$ were inferred. These traits were chosen because they are the 4 most frequent fertility-related diseases and disorders among first-lactation cows in Norway. Records of 503,683 first-lactation daughters of 1,058 Norwegian Red sires with first calving from 2000 through 2006 were analyzed with a 4-variate threshold sire model. Presence or absence of each of the 4 diseases was scored as 1 or 0 based on whether or not the cow had at least 1 veterinary treatment for the disease. The mean frequency was $3.1 \%$ for $\mathrm{SH}, 0.9 \%$ for MET, $0.5 \%$ for $\mathrm{CO}$, and $1.5 \%$ for RP. The model for liability had effects of age at calving and of monthyear of calving, herd, sire of the cow, and a residual. Posterior mean (SD) of heritability of liability was 0.06 (0.01) for SH, 0.03 (0.01) for MET, 0.07 (0.01) for CO, and $0.06(0.01)$ for RP. The genetic correlation between MET and RP was strong, with posterior mean (SD) $0.64(0.10)$. A negative genetic correlation $(-0.26)$ was found between RP and CO. The posterior distributions of the other genetic correlations included zero with high density, and could not be considered different from zero. The frequency of fertility-related diseases and disorders is very low in the Norwegian Red population at present, so there is limited scope for genetic improvement. However, this study indicates that reasonably precise genetic evaluation of sires is feasible for these traits given information from large daughter groups.
\end{abstract}

Key words: fertility, disease, reproductive disorder, threshold model

\section{INTRODUCTION}

Fertility-related diseases and reproductive disorders have been recorded routinely in the Norwegian health

\footnotetext{
Received November 4, 2009.

Accepted March 4, 2010.

${ }^{1}$ Corresponding author: bjorg.heringstad@umb.no
}

recording system since 1975 . Silent heat $(\mathbf{S H})$, cystic ovaries (CO), metritis (MET), and retained placenta (RP) are the most frequent fertility-related diseases and disorders. This group of diseases has so far not been included in the Norwegians Red total merit index, except RP, which together with ketosis and milk fever is included in "other diseases," a trait that receives a relative weight of $2 \%$ in the current total merit index (Geno, 2009).

Most genetic studies on fertility-related diseases have been based on relatively small data sets and have used methods that do not take into account that disease is scored as a categorical trait. Several studies have reported heritability estimates for one or more of the above-mentioned disease traits (e.g., Lyons et al., 1991; Hooijer et al., 2001; Zwald et al., 2004a; Heringstad et al., 2009), but there are few estimates of genetic correlations among these fertility-related diseases. Exceptions are Pösö and Mäntysaari (1996) who estimated a genetic correlation of 0.59 between MET and ovulatory disorders, and Van Dorp et al. (1998) and Zwald et al. (2004b) who reported genetic correlations close to 0 among MET, CO, and RP, and between CO and MET, respectively. In a recent study of reproductive disorders, including $\mathrm{SH}, \mathrm{CO}, \mathrm{MET}$, and RP, in Austrian Fleckvieh, Koeck et al. (2010) estimated genetic correlations that varied from very strong between RP and MET and between $\mathrm{CO}$ and $\mathrm{SH}$, to negligible between $\mathrm{CO}$ and $\mathrm{RP}$ and between MET and SH.

Relatively few genetic studies of fertility-related diseases have so far been published, but the range of estimates of genetic correlation for each trait combination is large, and some of the results are also somewhat contradictory.

The objectives of this study were to estimate heritability of and genetic correlations among $\mathrm{SH}, \mathrm{CO}, \mathrm{MET}$, and RP in first-lactation Norwegian Red cows. In this first genetic analysis of fertility-related diseases based on data from the Norwegian health recording system, these 4 diseases were chosen because they are the most frequent fertility-related diseases among first-lactation cows. 


\section{MATERIALS AND METHODS}

\section{Data}

Data were from the Norwegian Dairy Herd Recording System and included first-lactation daughters of Norwegian Red AI sires. Cows that had their first calving between January 1, 2000, and January 1, 2007, were included. Age at calving had to be from 20 to 36 mo. Heat synchronization is not commonly used in Norway, and cows that had received such treatment $(0.6 \%)$ were excluded from these analyses. The edited data set had 503,683 first-lactation cows, daughters of 1,058 Norwegian Red sires. The mean number of daughters per sire was 476 , ranging from 46 to 9,918 , with a mode of 227. Fewer than $10 \%$ of the sires had $<100$ daughters (the youngest sires that did not yet have a full progeny group), and about $10 \%$ of the sires had more than 330 daughters (elite sires). In total, 16,763 herds were represented in the data, and the mean number of cows per herd was 30 .

Absence or presence of each of the 4 diseases was scored as 0 or 1 , respectively, based on whether or not the cow had at least 1 veterinary treatment recorded within the first $5 \mathrm{~d}$ after calving for RP, and within 300 $\mathrm{d}$ after calving for $\mathrm{SH}, \mathrm{CO}$, and MET. The mean frequency was $3.1 \%$ for $\mathrm{SH}, 0.9 \%$ for MET, $0.5 \%$ for $\mathrm{CO}$, and $1.5 \%$ for RP. Here, SH included veterinary treatments diagnosed as silent heat, anestrus, and repeated breeding (Norwegian health card codes 331, 340, and 341; Helsetjenesten for storfe, 2009).

The sire pedigree file had 1,825 males, including the 1,058 with daughters in the data set, and their sires and maternal grandsires traced back as far as possible.

\section{Models}

A 4-variate threshold-liability model was used for analysis of the data. Similar models have previously been used for genetic analyses of mastitis and other diseases (Heringstad et al., 2004, 2005). The threshold model postulates an underlying continuous variable, liability $(\lambda)$, such that the observed binary response variable takes value 1 if $\lambda$ exceeds a fixed threshold, and 0 otherwise. The threshold and the residual variance are not identifiable in binary data analysis, so these parameters were set equal to 0 and 1 , respectively.

In matrix notation, the model can be written as $\boldsymbol{\lambda}=$ $\mathbf{X} \boldsymbol{\beta}+\mathbf{Z}_{\mathbf{h}} \mathbf{h}+\mathbf{Z}_{\mathrm{s}} \mathbf{S}+\mathbf{e}$, where $\boldsymbol{\lambda}$ is a vector of unobserved liabilities for the 4 traits; $\boldsymbol{\beta}$ is a vector of systematic effects including age at calving (17 classes) and month $\times$ year of calving ( 84 classes); $\mathbf{h}$ is a vector of random herd effects (16,763 classes); $\mathbf{s}$ is a vector of sire transmitting abilities; e is the vector of residual effects; and $\mathbf{X}, \mathbf{Z}_{\mathbf{h}}$, and $\mathbf{Z}_{\mathrm{s}}$ are the corresponding incidence matrices.

\section{Sampling and Convergence Diagnostics}

A Bayesian approach using Markov chain Monte Carlo methods (e.g., Sorensen and Gianola, 2002) was implemented. The data was analyzed using Gibbs sampling in the RJMC procedure of the DMU package (Madsen and Jensen, 2008). Based on trace plots and the convergence diagnostics method of Raftery and Lewis (1992), it was decided to discard the first 5,000 iterations as burn-in, and, thereafter, use a total chain length of 150,000 iterations. All samples after burn-in were used for posterior inferences.

\section{RESULTS AND DISCUSSION}

\section{Phenotypic Frequency}

The overall mean frequency was $3.1 \%$ for $\mathrm{SH}, 0.9 \%$ for MET, $0.5 \%$ for CO, and $1.5 \%$ for RP (Table 1). Only first-lactation cows were included in our study, and for some of the fertility-related diseases the frequency may be greater in later lactations. However, the incidence of all these reproductive diseases and disorders was much smaller than in other studies. For example, Zwald et al. (2004a) reported average lactation incidence rates of $8 \%$ for cystic ovaries and $21 \%$ for metritis (including RP) for US Holsteins. In a Dutch study, Hooijer et al. (2001) found an overall incidence of cystic ovarian disease of 7.7\%. Pösö and Mäntysaari (1996) reported 10\% ovulatory disorders and 3\% metritis for first-lactation Finnish Ayrshire cows, whereas Koeck et al. (2010) found incidences of $6.3 \%$ for $\mathrm{SH}, 9.6 \%$ for CO, $3.8 \%$ for MET, and $2.6 \%$ for RP in Austrian Fleckvieh cows. In a recent study, Johansson et al. (2008) reported frequencies of early reproductive diseases (occurring between 0 and 40 DIM) in first-lactation Holstein cows of $8.8 \%$ in Denmark, $3.9 \%$ in Finland, and $2.8 \%$ in Sweden, whereas the frequencies of late reproductive diseases (from 41 to $305 \mathrm{DIM}$ ) in the 3 countries was $1.4 \%$, $11.1 \%$, and $6.6 \%$, respectively.

The phenotypic frequencies in Table 1 show that cows with one of the diseases tended to have a higher frequency of other diseases. For example, cows with RP had a much higher frequency of MET (9.3 vs. 0.7), and cows with $\mathrm{CO}$ had a higher frequency of SH (10.8 vs. 3.0) than the average.

Although the overall mean frequencies of these 4 diseases were low, considerable phenotypic variation was found between daughter groups. The minimum disease frequency within sire was 0 for all 4 traits, whereas the 
Table 1. Overall mean disease frequencies (\%) of cystic ovaries (CO), metritis (MET), retained placenta (RP), and silent heat (SH), together with mean disease frequencies for groups of cows with absence (0) or presence (1) of each of the 4 fertility-related diseases

\begin{tabular}{|c|c|c|c|c|c|c|c|c|c|}
\hline \multirow[b]{2}{*}{ Disease } & \multirow[b]{2}{*}{ Overall mean } & \multicolumn{2}{|c|}{$\mathrm{CO}$} & \multicolumn{2}{|c|}{ MET } & \multicolumn{2}{|c|}{$\mathrm{RP}$} & \multicolumn{2}{|c|}{$\mathrm{SH}$} \\
\hline & & 0 & 1 & 0 & 1 & 0 & 1 & 0 & 1 \\
\hline MET & 0.9 & 0.9 & 2.4 & & & 0.7 & 9.3 & 0.8 & 1.7 \\
\hline RP & 1.5 & 1.5 & 1.7 & 1.4 & 16.1 & & & 1.5 & 1.8 \\
\hline $\mathrm{SH}$ & 3.1 & 3.0 & 10.8 & 3.0 & 6.2 & 3.0 & 3.6 & & \\
\hline
\end{tabular}

mean and maximum disease frequencies (\%) within sire were 0.4 and 3.7 for CO, 0.8 and 5.9 for MET, 1.5 and 6.8 for RP, and 3.0 and 10.0 for SH. The maximum number of daughters with disease per sire were between $82(\mathrm{CO})$ and $435(\mathrm{SH})$.

\section{Systematic Effects}

The models for all 4 traits included effects of age and month $\times$ year of first calving. Age at calving had the largest effect on CO. Liability to CO and RP increased with age at first calving, whereas liability to MET decreased with higher age. The highest liability to SH was found for intermediate age at calving. Distinct seasonal variations were revealed for $\mathrm{SH}$ and $\mathrm{CO}$, with similar patterns over years. The liabilities of $\mathrm{SH}$ and $\mathrm{CO}$ were greatest in winter and smallest during the spring and summer months. The difference between month $\times$ year classes was smaller for MET and RP, and although seasonal patterns were less clear, the highest liabilities of RP were found during summer months.

\section{Heritability}

Posterior distributions of heritability of liability to $\mathrm{SH}, \mathrm{MET}, \mathrm{CO}$, and RP are in Figure 1. The distributions were reasonably symmetric and had a posterior $\mathrm{SD}$ around 0.01 . Posterior mean was 0.06 for $\mathrm{SH}, 0.03$ for MET, 0.07 for CO, and 0.06 for RP (Table 2).

In spite of slightly different trait definitions, the heritability estimates (Table 2 ) were in close agreement with those of Zwald et al. (2004b), who estimated heritability of liability to cystic ovaries and metritis in first lactation of 0.04 and 0.06 , respectively. In the study of Zwald et al. (2004b) metritis included RP. Hooijer et al. (2001) estimated heritability of $\mathrm{CO}$ on the underlying scale of 0.10, and Pösö and Mäntysaari (1996) reported heritabilities transformed to the liability scale ranging

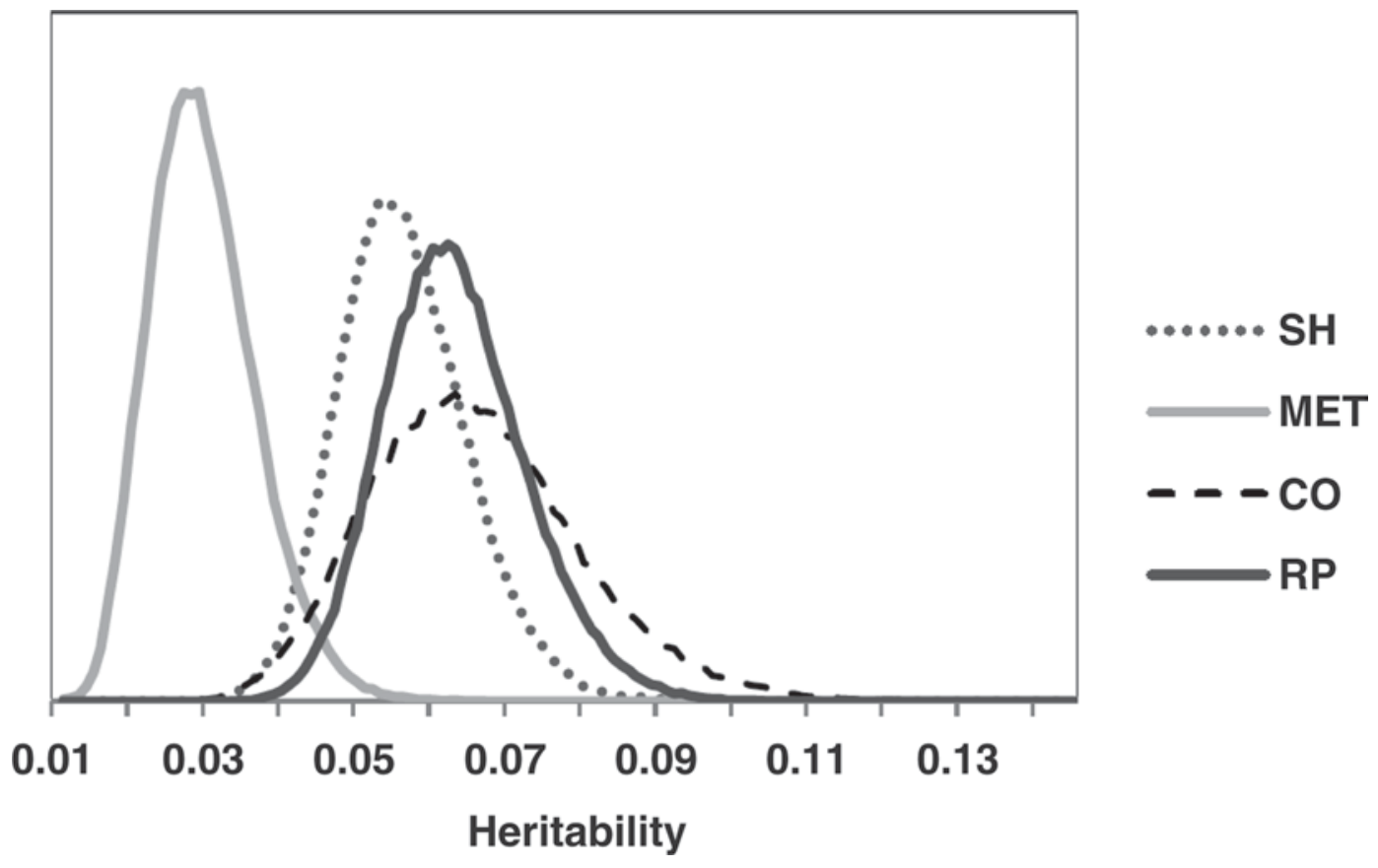

Figure 1. Posterior distributions of heritability of liability to (from the left) metritis (MET), silent heat (SH), retained placenta (RP), and cystic ovaries (CO). 


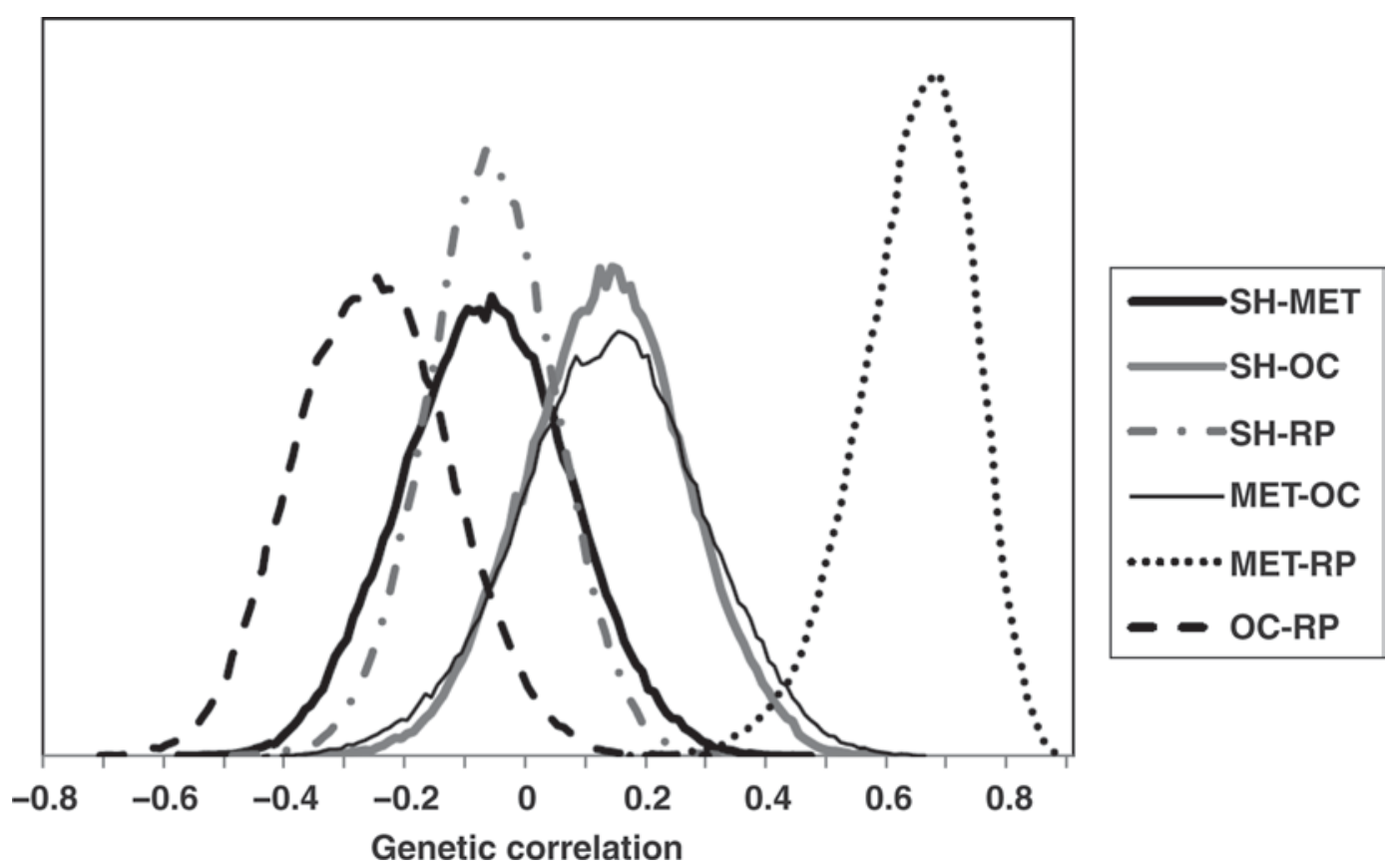

Figure 2. Posterior distributions of genetic correlations among liability to cystic ovaries (CO), metritis (MET), retained placenta (RP), and silent heat $(\mathrm{SH})$.

from 0.02 to 0.05 for ovulatory disorder and from 0.04 to 0.05 for MET.

The heritability of liability $\mathrm{SH}$ was higher than the estimates of Koeck et al. (2010) who estimated a heritability (SE) of SH of $0.012(0.015)$ from a logit threshold sire model and 0.005 (0.004) from a linear sire model. However, because of different scales these results are not directly comparable.

Heritability of liability of RP was slightly lower than the estimates of Heringstad et al. (2005, 2009) of 0.08 and 0.09, respectively. Schnitzenlehner et al. (1998) reported heritability estimates of retained placenta, transformed to the underlying scale, of 0.14 and 0.07 for first and second lactations, respectively. Other estimates of heritability of retained placenta ranged from 0.004 to 0.08 (Lyons et al., 1991; Van Dorp et al., 1998; Wassmuth et al., 2000; Koeck et al., 2010).

\section{Genetic Correlations}

Posterior distributions of the genetic correlations among the 4 diseases are given in Figure 2, and the posterior means and SD are in Table 2. The posterior SD were large, as illustrated in Figure 2, and results should therefore be interpreted with caution. The strongest genetic correlations were found between RP and MET,

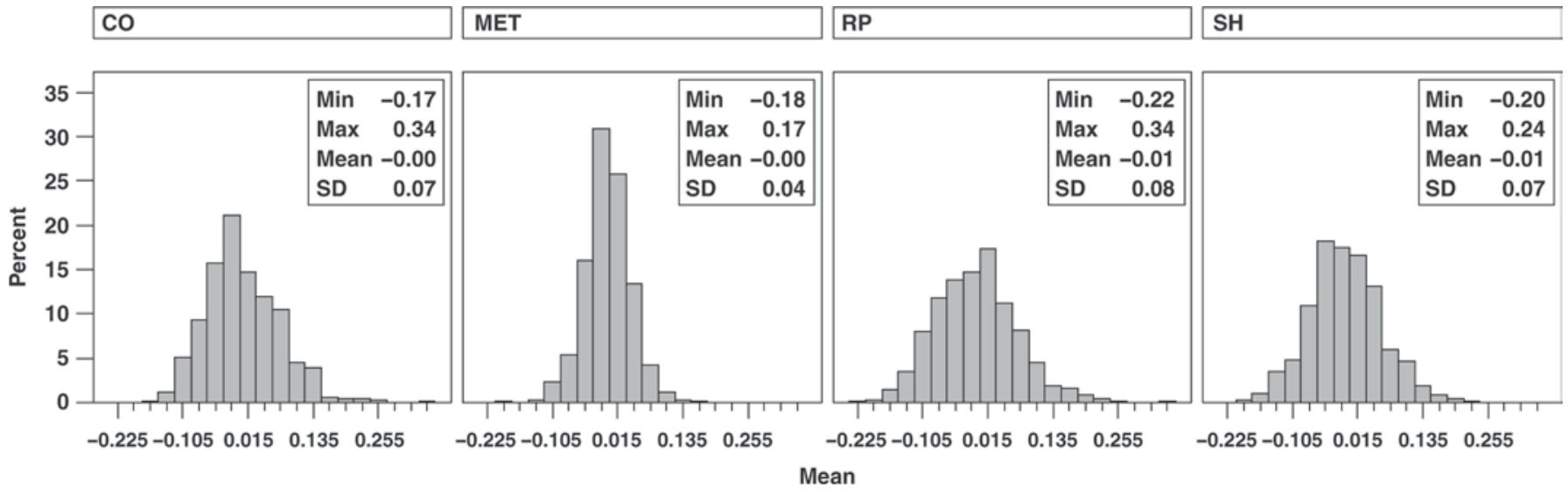

Figure 3. Distribution of sire posterior means for liability to cystic ovaries (CO), metritis (MET), retained placenta (RP), and silent heat (SH) for the 1,058 sires with daughters in the data set. 
Table 2. Posterior means (SD) of heritability (on the diagonal) and genetic correlations (above the diagonal) for liability to cystic ovaries (CO), metritis (MET), retained placenta (RP), and silent heat (SH)

\begin{tabular}{lcrrr}
\hline & CO & MET & \multicolumn{1}{c}{ RP } & \multicolumn{1}{c}{ SH } \\
\hline CO & $0.07(0.01)$ & $0.14(0.15)$ & $-0.26(0.13)$ & $0.13(0.13)$ \\
MET & & $0.03(0.01)$ & $0.64(0.10)$ & $-0.07(0.14)$ \\
RP & & $0.06(0.01)$ & $-0.06(0.10)$ \\
SH & & & $0.06(0.01)$ \\
\hline
\end{tabular}

with a posterior mean (SD) of $0.64(0.10)$. A negative genetic correlation $(-0.26)$ was estimated between $\mathrm{RP}$ and $\mathrm{CO}$, whereas the posterior distribution of the other genetic correlations included zero with high density.

This lack of genetic correlation among traits is in agreement with Zwald et al. (2004b) and Van Dorp et al. (1998), who estimated genetic correlations between cystic ovaries and metritis close to zero. In contrast, Pösö and Mäntysaari (1996) estimated a genetic correlation (SE) of 0.59 (0.25) between MET and ovulatory disorders. Koeck et al. (2010) reported genetic correlations (SE) of $0.85(0.28)$ between $\mathrm{CO}$ and $\mathrm{SH}$ and 0.39 (0.08) between RP and SH, whereas their estimated correlations between $\mathrm{CO}$ and MET, CO and RP, and between MET and SH could not be considered to be different from zero. Our estimated correlation between RP and MET of 0.64 disagrees with that of Van Dorp et al. (1998) who reported a genetic correlation close to zero, as well as with Koeck et al. (2010) who estimated a genetic correlation of 1 between these 2 traits. In a study in which several reproductive diseases were grouped together, Johansson et al. (2008) reported genetic correlations between early reproductive diseases (occurring between 0 and 40 DIM) and late reproductive diseases (from 41 to 305 DIM) in first lactation of 0.40 for Holstein and 0.25 for Nordic Red dairy cattle.

\section{Environmental Correlations}

Posterior mean of correlations among herd effects are given in Table 3. The correlations among herd effects were all positive and indicate that herds with a high frequency of one of the diseases tend to have more of the other diseases (e.g., herds with high frequency of $\mathrm{SH}$ tend to have more MET and RP compared with herds with less $\mathrm{SH}$ ). The residual correlation between
MET and RP was 0.49 (Table 3), suggesting associations between the two traits that could not be explained by genetic or herd correlations. This result may be due to a direct causal effect between RP and MET. All other residual correlations were negligible, ranging from -0.006 to 0.16 (Table 3 ).

\section{Genetic Evaluation of Sires}

The distributions of sire posterior means for the 4 traits for the 1,058 sires with daughters in the data set are given in Figure 3. The sharpest distribution of sire effects was found for MET, whereas RP showed most variation with sire posterior means ranging from -0.22 to 0.34 . The ranges of sire posterior $\mathrm{SD}$, which are a measure of the precision of the genetic evaluation, for the 4 traits are given in Table 4 . The SD, over all 4 traits, ranged from 0.03 to 0.13 . The range and precision of estimated sire effects indicate that significant genetic differences between sires exist for these traits. Reasonably precise genetic evaluation of sires is feasible for these traits given information from large daughter groups.

Because the frequency of each of the diseases is low, combining all reproductive diseases and disorders into a single trait in genetic evaluation could be an option. However, the lack of genetic correlation between traits, except between MET and RP, does not justify this approach.

\section{Model Assumptions and Limitations}

A threshold-liability sire model was used for analysis of the data. Preliminary analyses using linear sire models resulted, as expected, in much smaller heritability estimates for all traits (because heritability estimates

Table 3. Posterior means (SD) of herd variance (on the diagonal), herd correlations (above the diagonal), and residual correlations (below the diagonal) for liability to cystic ovaries (CO), metritis (MET), retained placenta $(\mathrm{RP})$, and silent heat (SH)

\begin{tabular}{lrrrr}
\hline & \multicolumn{1}{c}{ CO } & MET & RP & SH \\
\hline CO & $0.20(0.01)$ & $0.42(0.04)$ & $0.19(0.05)$ & $0.55(0.03)$ \\
MET & $0.12(0.03)$ & $0.16(0.01)$ & $0.40(0.04)$ & $0.31(0.02)$ \\
RP & $-0.01(0.03)$ & $0.49(0.01)$ & $0.06(0.00)$ & $0.22(0.03)$ \\
SH & $0.16(0.02)$ & $0.10(0.01)$ & $0.02(0.01)$ & $0.53(0.01)$ \\
\hline
\end{tabular}


Table 4. Precision of genetic evaluations: mean and range of sire posterior SD for liability to cystic ovaries (CO), metritis (MET), retained placenta $(\mathrm{RP})$, and silent heat $(\mathrm{SH})$

\begin{tabular}{lccc}
\hline Trait & Mean & Minimum & Maximum \\
\hline CO & 0.11 & 0.05 & 0.13 \\
MET & 0.07 & 0.04 & 0.08 \\
RP & 0.10 & 0.04 & 0.12 \\
SH & 0.09 & 0.03 & 0.12 \\
\hline
\end{tabular}

for binary traits from linear models are frequency dependent) and similar genetic correlations.

Censoring was not taken into account. This approach may have caused some selection bias. Cows with disease in early lactation (e.g., RP) have a greater risk of being culled than healthy cows and would thus not have the same opportunity to express diseases or disorders later in lactation.

Causal relationships between phenotypes may exist. For instance, RP may impair a cow's ability to show estrus or affect its risk of MET. This relationship could be taken into account by using a structural equation model (Gianola and Sorensen, 2004) and fitting causal relationships between traits. However, such models are very computationally demanding and could not be used to analyze large data sets at present.

\section{CONCLUSIONS}

Point estimates of heritability of liability were 0.06 for $\mathrm{SH}, 0.03$ for MET, 0.07 for $\mathrm{CO}$, and 0.06 for RP. The genetic correlation was strong (0.64) between MET and RP and negative $(-0.26)$ between RP and $\mathrm{CO}$, whereas the other genetic correlations were not considered to be different from zero. The frequency of fertility-related diseases and disorders is very low in the Norwegian Red population at present. The scope for genetic improvement is therefore limited, and there is probably no need to include these traits in the total merit index currently. However, this study indicates that reasonably precise genetic evaluation of sires is feasible for these traits, given information from large daughter groups.

\section{ACKNOWLEDGMENTS}

Access to the data was given by the Norwegian Dairy Herd Recording System and the Norwegian Cattle Health Service (Ås, Norway) in agreement number 004.2005. This work is part of project no $167893 / \mathrm{I} 10$ ("Avl for friskere kyr") financed by the Research Council of Norway (Oslo, Norway).

\section{REFERENCES}

Geno. 2009. Norwegian Red characteristics. Breeding objective. http://www.geno.no/GenoGlobal/Start-page/Norwegian-RedCharacteristics/ Norwegian-Red/ Accessed Dec. 10, 2009.

Gianola, D., and D. Sorensen. 2004. Quantitative genetic models for describing simultaneous and recursive relationships between phenotypes. Genetics 167:1407-1424.

Helsetjenesten for storfe. 2009. Årsmelding helsetjenesten for storfe 2008. (In Norwegian with English tables). Available at http:// storfehelse.tine.no/2545.cms Accessed November 27, 2009.

Heringstad, B., Y. M. Chang, D. Gianola, and G. Klemetsdal. 2004 Multivariate threshold model analysis of clinical mastitis in multiparous Norwegian dairy cattle. J. Dairy Sci. 87:3038-3046.

Heringstad, B., Y. M. Chang, D. Gianola, and G. Klemetsdal. 2005. Genetic analysis of clinical mastitis, milk fever, ketosis, and retained placenta in three lactations of Norwegian Red cows. J. Dairy Sci. 88:3273-3281.

Heringstad, B., X.-L. Wu, and D. Gianola. 2009. Inferring relationships between health and fertility in Norwegian Red cows using recursive models. J. Dairy Sci. 92:1778-1784.

Hooijer, G. A., R. B. F. Lubbers, B. J. Ducro, J. A. M. van Arendonk, L. M. T. E. Kaal-Lansbergen, and T. van der Lende. 2001. Genetic parameters for cystic ovarian disease in Dutch Black and White dairy cattle. J. Dairy Sci. 84:286-291.

Johansson, K., J. Pösö, U. S. Nielsen, J.-A. Eriksson, and G. P. Aamand. 2008. Joint genetic evaluation of other diseases in Denmark, Finland and Sweden. Interbull Bull. 38:107-112.

Koeck, A., C. Egger-Danner, C. Fuerst, W. Obritzhauser, and B. Fuerst-Waltl. 2010. Genetic analysis of reproductive disorders and their relationship to fertility and milk yield in Austrian Fleckvieh dual purpose cows. J. Dairy Sci. doi:10.3168/jds.2009-2955 (submitted).

Lyons, D. T., A. E. Freeman, and A. L. Kuck. 1991. Genetics of health traits in Holstein cattle. J. Dairy Sci. 74:1092-1100.

Madsen, P., and J. Jensen. 2008. An User's Guide to DMU. A package for analysing multivariate mixed models. Version 6 , release 4.7 . University of Aarhus, Faculty of Agricultural Sciences (DFJ), Dept. Genetics and Biotechnology, Research Centre Foulum, Tjele, Denmark.

Pösö, J., and E. A. Mäntysaari. 1996. Genetic relationships between reproductive disorders, operational days open and milk yield. Livest. Prod. Sci. 48:41-48.

Raftery, A. L., and S. Lewis. 1992. How many iterations in the Gibbs sampler? Pages 763-774 in Bayesian Statistics 4. J. M. Bernando, J. O. Berger, A. P. Dawid, and A. F. M. Smith, ed. Oxford University Press, London, UK.

Schnitzenlehner, S., A. Essel, and J. Solkner. 1998. Retained placenta: Estimation of nongenetic effects, heritability and correlations to important traits in cattle. J. Anim. Breed. Genet. 115:467-478.

Sorensen, D., and D. Gianola. 2002. Likelihood, Bayesian, and MCMC Methods in Quantitative Genetics. Springer-Verlag, New York, NY.

Van Dorp, T. E., J. C. M. Dekkers, S. W. Martin, and J. P. T. M. Noordhuizen. 1998. Genetic parameters of health disorders, and relationships with 305-day milk yield and conformation traits of registered Holstein cows. J. Dairy Sci. 81:2264-2270.

Wassmuth, R., D. Boelling, P. Madsen, J. Jensen, and B. Beck Andersen. 2000. Genetic parameters of disease incidence, fertility and milk yield of first parity cows and the relation to feed intake of growing bulls. Acta Agric. Scand. A Anim. Sci. 50:93-102.

Zwald, N. R., K. A. Weigel, Y. M. Chang, R. D. Welper, and J. S. Clay. 2004a. Genetic selection for health traits using producerrecorded data. I. Incidence rates, heritability estimates, and sire breeding values. J. Dairy Sci. 87:4287-4294.

Zwald, N. R., K. A. Weigel, Y. M. Chang, R. D. Welper, and J. S. Clay. 2004b. Genetic selection for health traits using producerrecorded data. II. Genetic correlations, disease probabilities, and relationships with existing traits. J. Dairy Sci. 87:4295-4302. 